University of Nebraska - Lincoln

DigitalCommons@University of Nebraska - Lincoln

Faculty Publications, Department of Child, Youth, and Family Studies

Child, Youth, and Family Studies, Department of

8-1-2007

\title{
Chinese Family Strengths and Resiliency
}

Anqi Xu

Shanghai Academy of Social Sciences, People's Republic of China

Xiaolin Xie

Northern Illinois University, DeKalb, Illinois, xiaolinx@niu.edu

Wenli Liu

Beijing Normal University, Beijing, People's Republic of China

Yan Ruth Xia

University of Nebraska-Lincoln, rxia2@unl.edu

Dalin Liu

Chinese Ancient Sex Culture Museum, Tongli and Shanghai, People's Republic of China

Follow this and additional works at: https://digitalcommons.unl.edu/famconfacpub

Part of the Family, Life Course, and Society Commons

Xu, Anqi; Xie, Xiaolin; Liu, Wenli; Xia, Yan Ruth; and Liu, Dalin, "Chinese Family Strengths and Resiliency" (2007). Faculty Publications, Department of Child, Youth, and Family Studies. 53.

https://digitalcommons.unl.edu/famconfacpub/53

This Article is brought to you for free and open access by the Child, Youth, and Family Studies, Department of at DigitalCommons@University of Nebraska - Lincoln. It has been accepted for inclusion in Faculty Publications, Department of Child, Youth, and Family Studies by an authorized administrator of DigitalCommons@University of Nebraska - Lincoln. 


\title{
Chinese Family Strengths and Resiliency
}

\author{
Anqi Xu \\ Xiaolin Xie \\ Wenli Liu \\ Yan Xia \\ Dalin Liu
}

\begin{abstract}
SUMMARY. Chinese family and marriage strengths and challenges are delineated in this article, including equity in marriage, affection, the ability to adapt to changes, mutual trust, compatibility, harmony, and family support. Despite the fact that Chinese households are getting smaller as a result of governmental policy and the broadening of housing markets, families remain crucial support networks, especially in the areas of socialization and intergenerational relationships. Current research on Chinese
\end{abstract}

Anqi Xu is Professor, Shanghai Academy of Social Sciences, People's Republic of China (E-mail: xaq@sass.org.cn). Xiaolin Xie is Associate Professor, School of Family, Consumer and Nutritional Sciences, Northern Illinois University, DeKalb, IL 60115 (E-mail: xiaolinx@niu.edu). Wenli Liu is Senior Researcher, Beijing Normal University, Beijing, People's Republic of China (E-mail: liuwenli200555@ yahoo.com.cn). Yan Xia is Assistant Professor, Department of Education and Family Studies, University of Nebraska-Lincoln, Lincoln, NE 68588 (E-mail: yxia@mail. unomaha.edu). Dalin Liu is Founder, Chinese Ancient Sex Culture Museum, Tongli and Shanghai, People's Republic of China.

Address correspondence to: Anqi Xu.

[Haworth co-indexing entry note]: "Chinese Family Strengths and Resiliency.” Xu, Anqi et al. Co-published simultaneously in Marriage \& Family Review (The Haworth Press, Inc.) Vol. 41, No. 1/2, 2007, pp. 143-164; and: Strong Families Around the World: Strengths-Based Research and Perspectives (ed: John DeFrain, and Sylvia M. Asay) The Haworth Press, Inc., 2007, pp. 143-164. Single or multiple copies of this article are available for a fee from The Haworth Document Delivery Service [1-800-HAWORTH, 9:00 a.m. - 5:00 p.m. (EST). E-mail address: docdelivery @ haworthpress.com].

Available online at http://mfr.haworthpress.com

(C) 2007 by The Haworth Press, Inc. All rights reserved. doi:10.1300/J002v41n01_08 
marriages and families is cited, outlining attitudinal changes regarding mate selection, divorce, and childbirth between genders, between older and younger generations, and between urban and rural residents. doi:10.1300/ J002v41n01_08 [Article copies available for a fee from The Haworth Document Delivery Service: 1-800-HAWORTH. E-mail address: <docdelivery@ haworthpress.com> Website: <http://www.HaworthPress.com> (0) 2007 by The Haworth Press, Inc. All rights reserved.]

KEYWORDS. Chinese families and marriages, family strengths, family resiliencies

\section{INTRODUCTION TO CHINESE MARRIAGES AND FAMILIES}

Chinese families have undergone tremendous changes in the past several decades as a result of socioeconomic developments, among them, the governmental one-child-per-family policy that has impacted family structure and family dynamics. The economic growth in major cities has prompted development of the housing market that gives young married couples the opportunity to purchase their own housing. Thus, the nuclear family has become the normative family structure. This chapter is an effort to delineate family strengths typical of contemporary Chinese families, and to provide current research on Chinese marriages and families that chronicle attitudinal changes on mate selection, divorce, and childbirth between genders, between older and younger generations, and between urban and rural residents.

\section{Chinese Family Strengths}

Chinese culture, being collective in nature, is well-known for its emphasis on family relationships and support. Families are described as close-knit units, manifested in three-generational households. However, the current norm of family structure today in China is no longer a threegenerational household; rather, it is the nuclear family. Research shows that despite the changes, family remains the main pillar of the social support network. Families are still greatly valued by the young and the old. Intergenerational relationships are not to be undervalued or underestimated. Child care and elder care remain families' responsibilities both in urban and rural China.

The studies of family strengths among Chinese families are scant. In the West, Stinnett and DeFrain (1985) identified major six strengths among American families: affection and appreciation, commitment, 
positive communication, the ability to manage stress and crisis effectively, enjoyable time together, and a sense of spiritual well-being. Xie, DeFrain, Meredith, and Combs (1996) conducted the first study of family strengths in China. They found that besides loyalty, family support, enjoying time together, families in China perceived a sense of harmony being an important aspect of family strengths. Again, this may be related to the collectivist culture that emphasizes unity and togetherness in the family. One example to illustrate this is that Chinese culture, like most other Asian cultures, tends to put the family name before first name, implying that families' needs take precedence over individuals' needs.

Xie, Xia, and Zhou (2004) conducted an in-depth interview study with 40 Chinese immigrants in the US to delineate major family strengths and challenges. The following family strengths were identified: family support; social support from friends and community; communication among family members; balancing host and heritage cultures, and spiritual wellbeing. These two studies seem to identify the recurring theme-family support to facilitate family functioning in China.

\section{Current Status of Chinese Marriages and Families}

Mate selection. This has been a significant research topic in the study of Chinese marriages and families for the following reasons: (1) mate selection is prelude to marriage and is the foundation of future family life; (2) though mate selection is a personal issue, and hinges on one's choices and interests, in reality, it is influenced by the families of origin, society, and culture.

Research indicates the following trends in mate selection among Chinese youths today: (1) youths consider personality more important than one's family background; (2) though men still emphasize chastity more than women, on the whole, the concept of chastity is downplayed by both genders; (3) education is valued in mate selection, especially among the educated group; (4) romance and affection are highly emphasized among the young, the educated, and professional groups (Li, 1989; Liu, 1996; Fei \& Xie, 1995).

In her study of 3,000 married men and women in Shanghai and Harbin, China, $\mathrm{Xu}(2000)$ found that the main criteria in mate selection were health $(60.9 \%)$, honesty $(53.4 \%)$, personality compatibility $(47 \%)$, and affection $(36.9 \%)$. Those with education held higher expectations for their future mates and were more careful in their selection process. Not only did they take into consideration their mate's financial status, but compatibility and affection. However, factors that influenced mate 
selection were multifaceted, such as gender, geographic regions, the family's financial situation, and housing conditions.

Studies in the past showed that arranged marriages were a common practice in China, with approximately two-thirds of marriages arranged in urban areas and even higher percentages in rural areas, especially those that were economically disadvantaged (Pan, 1987; Shen \& Yang, 1995; Xu, 1997). However, recent trends showed that arranged marriages were decreasing in rural areas, and even more rapidly in urban areas. Friends and colleagues took over the matchmaker roles that parents, relatives and neighbors used to play (see Table 1).

As friends and colleagues were more likely to introduce a perspective mate than relatives, youths were granted more freedom to choose their own mates. Today, in rural China, arranged marriages where both couples did not know each other before marriage and were not happy with the choices represents only $4.7 \%$, compared to $29 \%$ in 1966. Self-selection of a mate represents $56.7 \%$, compared to $32.8 \%$ in 1966 (Xu, 1997). Table 2 shows that a majority of the couples are happy about their own mate selection.

After 1949, dating was discouraged and frowned upon for several decades. Many couples went underground when dating. Because of the lack of entertainment centers and financial resources at the times, dating

TABLE 1. How couples met (in percent).

\begin{tabular}{|c|c|c|c|c|}
\hline & \multicolumn{2}{|c|}{ Cities } & \multicolumn{2}{|c|}{ Rural Areas } \\
\hline & $\begin{array}{l}\text { Beijing and } \\
\text { four other } \\
\text { cities }\end{array}$ & $\begin{array}{c}\text { Beijing and six } \\
\text { other cities }\end{array}$ & Gansu & Guangdong \\
\hline & 1982 & 1992 & \multicolumn{2}{|c|}{1996} \\
\hline Through Parents & 17.6 & 4.3 & 60.8 & 2.1 \\
\hline Through Relatives & 22.6 & 21.4 & 16.6 & 20.5 \\
\hline Through Match-Makers & & 7.7 & 0.8 & 25.2 \\
\hline Through Friends & 36.0 & 33.4 & 8.4 & 21.4 \\
\hline Own Self & 23.0 & 32.0 & 12.9 & 30.3 \\
\hline Through Work & 0.8 & 1.2 & 0.0 & 0.1 \\
\hline Through Agencies & & 0.1 & 0.0 & 0.0 \\
\hline Others & & & 0.5 & 0.4 \\
\hline Total & 100.0 & 100.0 & 100.0 & 100.0 \\
\hline $\mathrm{N}$ & 4878 & 5476 & 1330 & 1537 \\
\hline
\end{tabular}

Sources: Adapted from Pan (1987); Shen \& Yang (1995); Xu (1997). 
TABLE 2. Marriage decision making among rural couples at different periods (\%).

\begin{tabular}{|c|c|c|c|c|c|}
\hline \multirow[b]{2}{*}{ Marriage decision making } & \multicolumn{5}{|c|}{ Different Periods } \\
\hline & $1946-1966$ & $1967-1976$ & 1977-1986 & 1987-1996 & $\begin{array}{c}\text { Row } \\
\text { average }\end{array}$ \\
\hline $\begin{array}{l}\text { Arranged by Elders, } \\
\text { Not Knowing Each Other } \\
\text { Before Marriage }\end{array}$ & 25.2 & 13.9 & 8.2 & 3.8 & 12.8 \\
\hline $\begin{array}{l}\text { Arranged by Elders, } \\
\text { Not Happy with the Choice }\end{array}$ & 3.8 & 1.5 & 1.4 & 0.9 & 1.9 \\
\hline $\begin{array}{l}\text { Arranged by Elders, } \\
\text { Happy with the Choice }\end{array}$ & 38.2 & 46.7 & 42.4 & 38.5 & 41.4 \\
\hline $\begin{array}{l}\text { Own Choice, } \\
\text { Parents Happy }\end{array}$ & 24.1 & 32.6 & 43.1 & 50.2 & 37.5 \\
\hline $\begin{array}{l}\text { Own Choice, } \\
\text { Parents Not Happy }\end{array}$ & 0.8 & 1.0 & 1.4 & 1.8 & 1.3 \\
\hline $\begin{array}{l}\text { Own Choice, Parents } \\
\text { Deceased, or Did Not Care }\end{array}$ & 7.9 & 4.4 & 3.5 & 4.7 & 5.1 \\
\hline Total & 100 & 100 & 100 & 100 & 100 \\
\hline $\mathrm{N}$ & 477 & 613 & 1013 & 763 & 2866 \\
\hline
\end{tabular}

Source: Adapted from Xu (1997).

behavior was restricted to chatting at one's own home or strolling on the street (Xu, 1997). Su and Hu (2000) found that letter writing was the main communication instrument between couples. In their study of 20- to 30 -year-old youths in China, $\mathrm{Li}$ and Xu (2004) revealed that $47 \%$ of the couples wrote letters to express their affection for each other. This behavior was more popular among the educated group.

As to the number of dates couples had before marriage, in a study that involved 1,600 married couples, Xu (1997) found that the average number of different partners that they dated before marriage was 1.5 for each participant. Two thirds married the first and only person they dated. Only $10.8 \%$ had dated two or more people. Li and Xu (2004) found that among youths, the average number of dates was 3.3. Sixty-eight percent had one to three people with $11 \%$ having dated six or more people. Because of the limited selection pool among the middle aged and older groups, many of them dated fewer people.

Pan and Jen (2000) conducted a random study of dating behavior among college students on 150 campuses in 1997. Results showed that $41.4 \%$ of students had kissed, $26.7 \%$ had sexual touches, and $10.1 \%$ had sexual intercourse. Another study involved 5,070 university students on 26 campuses in 14 provinces revealed similar results: $11.3 \%$ had 
sexual intercourse. Among those students who had engaged in sexual intercourse, gender differences were also revealed: $52.2 \%$ of male participants had one sexual partner versus $67.9 \%$ of the females; $22 \%$ of males had six or more sexual partners versus $18.3 \%$ of the females (Research on Sex Education among College Students, 2001).

Marriage. Marriage is a salient life event. Marriage attitudes are reflections of family, social and cultural values. They influence marriage behaviors and family life. It is still against the law in China to cohabit. The majority of Chinese are against this behavior, but it is becoming more accepted among the younger generation. Lu (1997) found some age differences in their consensus with the statement "No cohabitation unless married": $65 \%$ of those 36 years and younger, versus $68 \%$ of those 35 to 55 years old, and $75 \%$ of those 55 and older agreed with that statement. In another study on a similar topic, Li and Xu (2004) found that half of their 683 participants approved of cohabitation conditionally. To the statement, "It was all right to cohabit if the couple planned to get married," $51 \%$ agreed, and 25\% disagreed. There was also a gender difference in response to that statement. $17 \%$ of male participants disagreed versus $33 \%$ of the females. In the same study, $49 \%$ reported kissing on a date, $35 \%$ had sexual intercourse, $11 \%$ cohabitated, and $11 \%$ got pregnant. It also was reported that the main constraints for sexual involvement were lack of passion (37.4\%), fear of the consequences (20.3\%), and that this behavior was immoral (4.7\%) (Pan, 1995).

Chastity is considered an important value in traditional Chinese culture. Premarital sexual involvement is scorned and regarded as a social vice. However, among the youths today, it has become more acceptable. One study on sexual attitudes that involved 541 university students revealed that $48 \%$ of the students considered that "chastity was important," $33 \%$ believed that "the concept was too traditional, and should be abolished," $19 \%$ did not have an opinion one way or the other. Gender differences were found in this study with $55 \%$ of females versus $38 \%$ of males considering chastity important; $36 \%$ of males and $31 \%$ of females considered this concept too old-fashioned; $26 \%$ of males and $13 \%$ of females did not have an opinion one way or another (Zhen et al., 2000). In another study, among those 20 to 30 years of age, $34 \%$ considered chastity outdated; $64 \%$ of males and $84 \%$ of females thought the concept unfair for women (Li \& Xu, 2004).

Husband-wife relationships and their role identities. Chinese culture emphasizes social stability and family harmony. Family and social needs takes precedence over individual needs. This leads some studies to posit that Chinese marriages are of high stability, but low quality (Fu, 1988; 
Chui, 1994). However, studies show that the majority of married couples report high satisfaction in their relationships. In his study involving 5,000 couples in seven cities in China, $36.1 \%$ of wives versus $37.6 \%$ of husbands reported that their marriage was highly satisfying, $38.1 \%$ of wives versus $40.9 \%$ of husbands reported that they were satisfied, $24.9 \%$ of wives versus $21.3 \%$ of husbands reported an average level of satisfaction, and only .9\% of wives and .2\% of husbands report they were highly unsatisfied (Shen \& Yang, 1995).

Another study of a similar nature revealed consistent results: $42.2 \%$ of the participants in Beijing were highly satisfied about their marriage. $49.4 \%$ reported they loved their spouse deeply, and $49.5 \%$ reported that their spouse loved them deeply (Li, 1996). Xu (1997) conducted a study on marital quality in Shanghai and its four surrounding regions. In the study, the majority of the respondents reported they were satisfied or highly satisfied with their marriage. Only a quarter of the respondents reported an average level of satisfaction. Those who described having equity in their marriage, mutual trust, and compatibility reported higher satisfaction scores. Therefore, it can be concluded that these are major characteristics in happy marriages. In the same study, $89 \%$ of the couples had not considered separation or divorce in the past year, only $0.7 \%$ thought about divorce often, $72.8 \%$ of the couples did not believe that their spouse would leave them, and only $0.7 \%$ believed that they would divorce their spouse. This shows that most Chinese marriages enjoy stability as well as satisfaction. Factors that lead to marital satisfaction include affection for each other, knowing each other well before marriage, the ability to adapt to changes, and compatibility (Xu \& Ye, 2002).

Over the past several decades, women's roles have changed dramatically. Since the 1950s, the Chinese government has adopted policies that allow and encourage women to work outside the home. Today, the majority of women have jobs outside the home. These policies also help reduce the gender gap in education levels, career choices, income, and old age support. In a 2000 study of women's social status, involving 19,449 participants age 18 to 64 in 30 provinces, the majority of respondents disagreed that "women should avoid becoming superior to their husband in social status." Only $18.5 \%$ agreed with that statement. This is 3\% lower compared to a similar study done in 1990 (The Second Investigation on Chinese Women's Social Status, 2001). A more recent study echoed similar results. The majority of the respondents believed that the husband and wife should share responsibilities in household chores and children's socialization and education. As to the statement, "The husband's role was to make money, whereas the wife's role was to 
take care of the family," only $2.8 \%$ of those 20 to 30 years old agreed, and $14.7 \%$ somewhat agreed; $2.8 \%$ agreed that the woman's careers should not supersede men's careers, and $10.1 \%$ somewhat agreed. $8.6 \%$ of the respondents agreed that "men should not do housework" (Li \& $\mathrm{Xu}, 2004)$.

As a result of their work-force participation, women's decision-making power at home has increased. This was supported by the Second Investigation on Chinese Women's Social Status (2001): 67.4\% of the participants reported joint decision making or the wife's sole decision making in career choices. This was an increase of $17.3 \%$ compared to 1990. Also, $60.7 \%$ of the wives were involved in decision making in family financial investment, and $70.7 \%$ participated in decision making about housing purchases. This was an increase of 10.2 and $15.1 \%$, respectively. In the same study, $88.7 \%$ of women versus $90.9 \%$ of men solely decided what personal items they purchase, and $91.3 \%$ of women versus $94 \%$ of men solely decided how much support they provided their parents (The Second Investigation on Chinese Women's Social Status, 2001). Though the hours spent on daily housework were reduced for both genders, the fact that women still shouldered the majority of the housework did not change. They spent an average of 4.01 hours a day on the household, 2.7 hours more than their male counterparts. Urban women spent an average of 2.9 hours a day, 1.6 hours more than urban men (The Second Investigation on Chinese Women's Social Status, 2001).

There are concerns that globalization and market competition jeopardize women's labor-force participation and their income. In recent years, women's employment rate has been declining. At the end of 2000, $87 \%$ of urban women aged 18 to 64 years old were employed. This is $6.6 \%$ lower compared to men's employment rate. Both rates dropped compared to those in 1990, but the decrease is more visible for women than for men. Despite the fact that women's income increased in the past ten years, the gap between men's income and women's income widened. Women made $70.1 \%$ of what men made in townships, $7.4 \%$ less than what men made in 1990 (The Second Investigation on Chinese Women's Social Status, 2001).

Marital conflicts. Xu and Ye (1999) concluded that household chores, disagreement on children's education, and finances, but not extramarital affairs or family violence as depicted in the media, were the major causes for marital conflicts. Household chores accounted for $51.7 \%$ of the marital disputes, disagreements on children's education was $38.1 \%$, financial issues, $23.7 \%$, in-laws issues, $14 \%$, the unhealthy habits of one spouse, $13.3 \%$, and sexual disharmony, extramarital affairs, or giving 
birth to a girl together totaled only $2 \%$. Geographic locations account for differences in marital conflicts. In a rural area in Gansu, China, an economically-depressed province, major conflicts centered on finances and division of household chores. In Shanghai, a metropolitan city, living standards were relatively higher than other parts of the country, and parents held high academic expectations for their onlies, therefore, it was not surprising to see that the main source of marital discord was disagreement on children's education. This was consistent with Sa's (1995) study that urban couples argued about children's education more than rural couples, whereas rural couples fought about finance more than their urban counterparts.

In their study about the frequency of arguments among marital couples, when asked how often they argued in the past year, $2.4 \%$ reported "often," $13.2 \%$ reported "sometimes," $36 \%$ stated "seldom," and $48 \%$ reported "never." Most of arguments and fights occurred within 3 to 7 years of the marriage, with the least occurring after 30 years of marriage. After their arguments and fights, only $2 \%$ of the couples said they made no compromises; $46.7 \%$ of urban husbands versus $30.2 \%$ of their rural counterparts made initial repair attempts. This was in comparison of $12.7 \%$ of urban wives versus $27 \%$ of rural wives. Fighting behaviors were different for husband than wives. During fights, husbands tended to do the following: yell and scream (51.2\%), silent treatment (46.9\%), physical violence (19.9\%); while wives tended to do the following: silent treatment $(77.6 \%)$, crying $(70.1 \%)$, and screaming and yelling $(41.1 \%)$ (Xu \& Ye, 1999). Because of a lack of availability of marriage and family counseling programs, extended families or networked families tended to play a role in couple-conflict resolution: $29.5 \%$ of wives talked to their family of origin about the fight, $12.4 \%$ of wives went to stay at their own parents' place, $29.4 \%$ of parents and relatives offered help to the fighting couples at one point, $1.8 \%$ of the parents and relatives voiced disapproval of their idea of divorce, and only .4\% supported it. However, in some extreme situations when families of origin were overinvolved, couples' relationships deteriorated faster than anticipated.

Marital dissolution. When marriages become unsalvageable, marital break-ups are likely to occur. Marital dissolution is influenced by different factors, such as geographic locations, social and cultural issues, family structure, and family networks. Divorce is still considered a social stigma that has a negative impact on one's reputation and on social stability.

As more people crave better marital relationships, and as the social and psychological costs related to divorces lessen, people, especially today's 
urban youths, adopt a more tolerant attitude toward divorce. In his study of 541 university students, Zhen et al. (2000) revealed that $44.4 \%$ of students believed that "the increasing divorce rate was a byproduct of social growth"; $68.6 \%$ believed that divorce was a private matter; $87.3 \%$ believed that divorce was a better option than a conflictual marriage. This was consistent with Li and Xu's (2004) study that reported only one third of their respondents believed that divorce had a negative impact on one's reputation and was detrimental to a child's emotional and physical health. Though single youths were less likely than married couples to acknowledge any negative impacts of divorce, when asked to respond to the statement, "Love was the foundation of marriage, and if love died, marriage should end," only $36.6 \%$ of the former group agreed.

However, married couples are more discreet about divorce than youths for fear that it will be detrimental to their children and to themselves. In a study conducted by the Shanghai Academy of Social Sciences in 2002,53.8\% agreed that for the sake of children, a couple should maintain their marriages despite the fact that they were not happy together. $70.6 \%$ agreed that divorce affected one's reputation to some degree.

The last half of the twentieth century witnessed the ebb and flow of divorce rates in China in light of political, social, and economic changes. At the beginning of 1950s after the war ended and a new political party came into power, many arranged marriages or marriages involving violence and abuse crumbled under the new Marriage Law. The divorce rate went up dramatically during that period, and decreased around the mid-1950s. The economic growth after natural disaster in the late 1950s triggered another hike in the divorce rate, but quickly cooled down. The late 1970s saw another increase in the divorce rate, but of relatively smaller magnitude compared to the previous two periods of increased divorce rates. It has maintained the same momentum till now (see Figure 1). This recent increase in divorce rate reflected people's changing attitudes toward divorce, and their higher expectations for marriage against the backdrop of an improved living environment and economic growth $(\mathrm{Xu}$, 1995; Zhang, 1994). In 1980, the crude divorce rate was $0.35 \%$, and in 2004 it was $1.28 \%$. Geographic regions made a difference in divorce rates. In 1980, the highest crude divorce rate was $3.98 \%$ in Sinjan, the lowest was $0.16 \%$ in Shanxi; whereas in 2004, the highest was $3.51 \%$ in Shanxi, the lowest was $0.46 \%$ in Tibet.

Some studies suggest that differences in people's belief systems were likely to loosen social coherence and lead to a further increase in the divorce rate (Glenn \& Supancic, 1984; Glenn \& Shelton, 1985; Breault \& Kposowa, 1987). In China, family structure, social coherence, ethnic 
FIGURE 1. Divorce trend in China from 1980-2004.

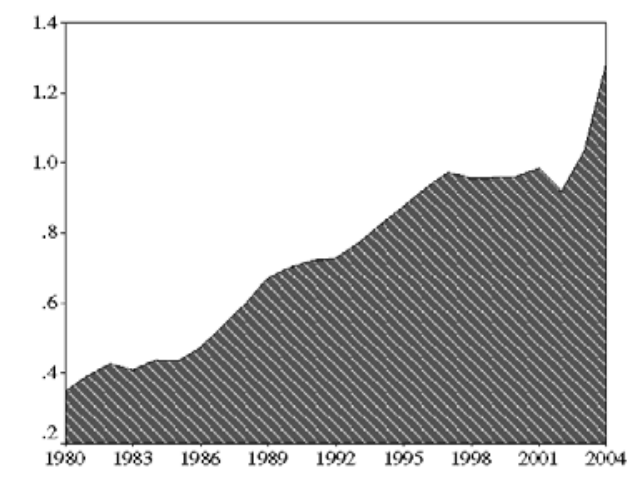

Source: Adapted from Chinese Statistics Bureau $(1990,2005)$.

culture, and implementation of marital law all influenced divorce rates in various locales in China. Low childbirth rates, small family structures, educational levels, job mobility, improved living standards, and membership in an ethnic minority all were associated with a higher divorce rate (Xu, 1997).

Socioeconomic growth in China has impacted people's views on marriages and families. It is anticipated that divorced families, singleparent families, singlehood, and childless marriages are likely to become more accepted and acknowledged. However, because of differences in value systems between urban and rural areas, between the coastal areas and inlands, and because of the lack of a government-sponsored social security system in rural China, many couples have only their families to rely on during crisis or transition stages.

Family structure. Traditional Chinese families are child-centered rather than couple-centered. Intimacy between couples is thought to have a negative impact on their commitment and responsibility to their extended family. The idea of the three- or four-generation family household remains a stereotype. Even in rural China, nuclear families are the main family structures with a household size of 3 to 6 persons. Married siblings no longer share a large household. The current small-scale economic model, different from the extended family structure, and conflictful in-law relationships help diminish the family size (Fei, 1983; Du, 1992). Table 3 
TABLE 3. Family structures in urban and rural China.

\begin{tabular}{lrrlrr}
\hline Family structure & Urban (\%) & Rural (\%) & $\begin{array}{l}\text { Family size } \\
\text { (person) }\end{array}$ & Urban (\%) & Rural (\%) \\
\hline Single & 3.38 & 2.44 & 1 & 3.63 & 2.59 \\
Single-Parents & 1.13 & 0.99 & 2 & 10.29 & 6.76 \\
Husband-Wife & 8.36 & 5.11 & 3 & 37.48 & 20.27 \\
Nuclear Family & 61.17 & 65.58 & 4 & 22.61 & 31.69 \\
Stem Family & 19.51 & 22.79 & 5 & 14.87 & 20.62 \\
Extended & 2.32 & 0.79 & 6 & 6.26 & 10.28 \\
Skipped Generation & 1.23 & 0.49 & 7 & 2.68 & 4.55 \\
Others & 2.71 & 1.18 & 7 or more & 2.18 & 3.23 \\
Total & 100.00 & 100.00 & Total & 100.00 & 100.00 \\
N & 3,577 & 9,334 & N & 3,578 & 9,335 \\
& & & Mean Person & 3.90 & 4.29 \\
& & & SD Person & 1.53 & 1.55 \\
\hline
\end{tabular}

Source: Adapted from Shen, Chen, \& Gao (2000).

lists the results of a study that involved 12,913 families in eight cities and townships, and 18 rural areas.

In light of the above discussion, the following can be concluded about the current Chinese families and marriages:

1. Despite the fact that Chinese family size is getting smaller, and extended families are not the norm, families remain a crucial part of the Chinese support network. They still play a critical role socially, economically, and emotionally. They provide mutual support in times of family crisis or during difficult family situations (Pan, 1987). Research shows that besides limited protection from government-sponsored social security and pensions from employers, many senior citizens rely on the support of their adult children and families. In rural China, because of lack of social security, family support is even more prominent and critical. Family remains the major elder-care institution. The main elder-care providers in rural areas tend to be daughters-in-law (Zhang, 2001).

2 . The tight housing market has an impact on family structure, especially in the city (Fei, 1982; Pan et al., 1997). Many young-married couples move in with their parents as a result of the lack of housing for themselves. They also rely on their parents for childcare. However, as the country's economic growth continues, and the housing market broadens, the job opportunities many youths enjoy 
today allow them to purchase their own housing and diminish their dependence on their parents. This is also true in rural area where the economic growth allows young families to build their separate houses and as such, many nuclear families are formed (Fei, 1983; Lei, 1994).

3. The recorded household size in each city may not be accurate because of job mobility. The purpose of recording household size in the past was to control population growth and to decide on the amount of housing each family unit was entitled to (Ding, 1992; $\mathrm{Xu}, 1995)$. With the economic growth and commercialization of housing market, the recorded size per household may not reflect the actual number. Therefore, it necessitates cautious interpretation when data are being used.

Childbirth. The late 1970s witnessed the influential one-child-per-family childbirth control policy with the exception that some rural families were allowed to have a second child after a four-year gap. Ethnic minority families and families in sparsely-populated areas were also allowed to have two children. The number of children per woman aged 15 to 49 was 1.51 in 1995, and it decreased to 1.17 in 2003. In 2004, 69.3\% of families had one child, $27.3 \%$ of families had two children, and $3.4 \%$ of families had three children (State Statistics Bureau, 1996, 2005). The lifetime childbirth rate for fertile women was 1.81: 1.22 in urban areas, and 1.98 in rural areas; $83 \%$ of married women used contraceptives; $81 \%$ of families believed that birth control is still the woman's responsibility (see Figure 2).

Traditional Chinese culture holds that having a child protects one's old age, and the more children one has, the more blessings. However, with more women being educated and the implementation of family policy, some youths in metropolitan cities today opt for the DINC (Double Income No Children) lifestyle. Dong (2001) found that $14.1 \%$ of youths

FIGURE 2. Who is responsible for birth control.

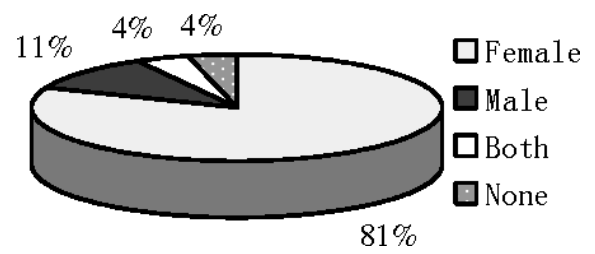

Source: Adapted from the Second Investigation of Chinese Women's Social Status (2000). 
in five metropolitan cities consider a childfree marriage ideal. Lo and Fen (2001) found similar results in a survey of 681 university students: $15.9 \%$ of students said that they would not have any children after marriage. As to the response to the statement, "Childless marriages were incomplete marriages," only $11.5 \%$ agreed, $33.6 \%$ somewhat agreed, $22.8 \%$ somewhat disagreed, and $7.5 \%$ disagreed; $24.6 \%$ were undecided (Li \& Xu, 2004). These studies suggested that having children was no longer considered the continuity of ones hopes and dreams. Youths' views on childbirth were becoming multidimensional.

Socialization of only children. The Chinese government implemented the one-child-per-family policy in 1979 to curtail population growth, which was predicted to reach 2.1 billion in 2080 if left uncontrolled (Tseng et al., 1988; Wang et al., 2000). Since its implementation, this policy has raised concerns about its impact on only children. Wang et al. (2000) found that attitudes toward only children remained the same over the years. Only children were reported to be overprotected by their parents and grandparents, and therefore, would experience disadvantages in their physical, social, emotional, and psychological development. Many Chinese speculated that only children, or "little emperors," would grow up to be spoiled, self-centered, non-cooperative, maladjusted, and lacking in the virtues that Chinese emphasize (Falbo et al., 1989).

Research on only children have focused on personality traits, behavior characteristics, and academic performance, and have reached mixed results. Liu et al. (2003) found in their study of psychosocial attributes that only children reported a higher level of anxiety and depression than those with siblings. This study was in sharp contrast to Yang et al. (1995) who previously found that only children reported a lower level of anxiety and depression, regardless of age, than sibling children. Tseng et al. (1988) found gender differences when they compared behavior problems between only children and sibling children. Boys who were only children did not differ from those with siblings. However, girls who were only children reported a higher level of depression. This result was compounded by the number of children preferred by parents and the dwelling-place of the families. Specifically, this effect was more pronounced in rural China. Jiao et al. (1986) compared only children and sibling children and found that the former had undesirable personality characteristics. In their study, sibling children scored higher than only children in independent thinking, persistence, cooperation with peers and behavior control, whereas only children scored higher in frustration tendencies and egocentrism than sibling children. Poston and Falbo (1990) reported similar results in their large-scale study of Chinese children in 
first and fifth grades from rural and urban China. The only difference between these groups was found in academic achievement, where only children enjoyed more advantages than sibling children. This result was confirmed in their subsequent study that involved 4,000 children from the third and sixth grades in four provinces in China. Only children reported a higher level of academic performance than sibling children and no significant difference was found in personality attributes or character development (Falbo \& Poston, 1993).

Several factors influenced the results of the studies. These factors included methods of data collection, age of only children when data were collected, geographic locations of only children, and the use of appropriate instruments. First and foremost, methods of data collection varied from teachers' or parents' perceptions of only children to self perceptions. Second, the age of only children when data were collected varied from kindergarten to college age, with most studies focusing on elementary school students. Zhang et al. (2001) stated that a negative description of only children as "little emperors," "stubborn," "easily loses his/her temper," etc., predominated in the younger age group (3-5 years old). Once the child was getting older, those negative descriptions dropped, and positive description rose. Falbo (1982) suggested that by the time these only children became young adults, many differences reported in the research studies between only children and sibling children may have been eradicated or reduced. Third, Poston and Falbo (1990) reported that the majority (90\%) of only children lived in the urban areas of China. Fourth, the use of culturally-appropriate and sensitive instruments was critical. Many studies that measured personality characteristics used instruments developed in the West, leading to issues related to validity and cultural sensitivity (Polit \& Falbo, 1987; Wan et al., 1994).

The studies of only children have received much attention in the past several decades. Recent studies seemed to point to more positive results (Wan et al., 1994; Wang et al., 2000). Wang et al. (2000) posited that one must incorporate an understanding of Chinese culture when studying only children in China. Chinese families tend to live in close proximity, thus, creating opportunities for children to interact with each other. They may be only children in each individual family, but they do not lack playmates.

In sum, research studies on only children in China had inconsistent results, with some painting a negative and deficit picture of only children, and others painting a neutral or positive one. However, recent studies lean toward the latter trend. A more thorough analysis of only children has concluded that only children and sibling children were not 
different from each other significantly in personality, behaviors, and character development. However, one difference seems to be consistent over time, the difference in academic achievement, with only children being in the more advantageous position than sibling children. This was consistent with Fong (2005) who found that children with few siblings or no siblings receive more parental investment. There is no exception for daughters, who are also encouraged to pursue higher education and competitive careers.

Intergenerational relationships. Confucianism, a traditional philosophy still impacting Chinese families, emphasizes family hierarchy and social and family harmony (Ho, 1981; Hsu, 1985). Inherent in Confucianism is the value of filial piety, which demands respect and obligation to aging parents, honoring the family name, and emphasis on group harmony rather than individual gratification or identity (Wong, 1998). Filial piety encompasses authority, power hierarchy, and family lineage. As such, Chinese families are often described as highly cohesive, partially due to the cultural emphasis on harmony and mutual obligations, and the low tolerance for overt family conflicts (Chow, 1999).

Traditionally, the Chinese family was a very strong institution. Because of economic and social reforms, Chinese families have gone through numerous changes in the past several decades. These changes include the widening housing market, increasing divorce rates, smaller family size, and greater mobility among youths. Pei and Pillai (1999) found that $90 \%$ of rural elderly had adult children living in the same village, whereas only $44 \%$ of their urban counterparts had adult children living in the same city due to job mobility. As such, family and household size are getting smaller. The traditional partrilocal family where parents and married sons share co-residence is now giving way to the neolocal family where young adults are residing in separate housing units. Consequently, compared to previous generations, older people in China today are more likely to maintain separate living households from their adult children than in the past (Chen \& Silverstein, 2000). Interestingly, Treas and Wang (1993) found that $79 \%$ of men and $65 \%$ of women aged 60 and older in metropolitan Shanghai favored a separate residence. Education and resources were related to their preference for a separate residence. Unger (1993) revealed that older people with a pension or work income were more likely to live separately from their adult children. Similarly, $\mathrm{Hu}$ and Ye (1991) found that higher-educated elderly were also more inclined to have their own housing units. Though in a separate residence, they also preferred living in the vicinity of at least one of their adult children. Some researchers have dubbed the term networked family to describe 
the intergenerational linkages to provide support when needed (Pan \& Ruan, 1995; Xu, 1995). Chinese families have long been described as a corporate kin group that cared for the welfare of all family members and were bound by common goals and interests (Tu et al., 1993). Through the networked family, the norm of reciprocity between the elderly and their adult children is often observed. For example, studies have shown that over half of all elderly helped their adult children with housework and child care (Hu \& Ye, 1991).

On the other side of the care spectrum, Yang (1996) stated that in the traditional Chinese family, support for elders was not uniform, but rather varied by gender. Sons were usually expected to support their parents financially. In Gui's study (1988), he found in rural China that sons provided the most in medical care, then spouses, and daughters last.

Likewise, in other places in China, of those legally responsible for the elder, $30 \%$ were oldest sons, $10 \%$ oldest daughters, and $31 \%$ other children (Chinese Population Information and Research Center, 1990). Zhan and Montgomery (2003) investigated the changing dynamics of caregiving in urban China against the backdrop of economic reforms and cultural emphasis of xiao (filial piety). Their study showed "a decline in the patrilocal tradition of caregiving." Taking care of the elderly was shifting from sons' responsibility to daughters' responsibility. However, the authors were concerned that those female caregivers today with fewer children, who were more financially dependent and more likely to live longer, faced challenges in future elder care for themselves.

The notion of having daughters as the caregivers is undergoing changes. With the one-child-per-family policy, parents in urban China were willing to invest in their only child's education, be it a boy or girl. Tsui and Rich (2002) revealed that parents held similar expectations and put forth a similar investment for boys and girls from only-child families. Therefore, there is no guarantee that girls would be available to take care of their aging parents, because the education opportunity granted to them today would allow them to have better job opportunities and to move away from their parents. This is consistent with Chen and Silverstein's (2000) study that revealed that the number of children and the gender of children were not significantly related to elder support, rather, having at least one proximate child increased the likelihood of receiving support.

As a result of changes at the family and state levels, researchers cautioned that the family may not remain the panacea for elder care in current China. In fact, the increasing number of older people in China necessitated involvement not only from the family level but also from the state level in elder care. Pei and Pillai (1999) concluded from their 
study that the following factors mattered at the family level: the number of living adult children; having sons in the family; and the amount of monetary support from adult children. Whereas, at the state level, the following variables were important: a pension; state financial subsidies; and the availability of medical services. Geographic locations mattered as well. In the same study, rural elderly received more financial aid from their adult children than their urban counterparts, while urban elderly received more pension income than rural elderly.

Meanwhile, young adults' attitudes towards elder care are changing. They express less commitment to elder care if there is conflict between employment and caregiving (Zhan, 2004a). Living in a three-generation household does not help improve the attitude either. Zhan (2004b) found that living arrangement impacted today's Chinese young adult's attitudes toward filial responsibility in a negative manner. Young adults from three-generation households were reported to be less committed to their sense of obligation to elder care.

Overall, intergenerational relationships in China are undergoing some changes. The traditional patrilocal family is gradually replaced by the neolocal family as a result of an increase in housing construction, a decrease in family size, people's attitudes towards co-residence, and job mobility among youths. Meanwhile, because of a lack of a national pension system for elderly at the moment, and the deeply-rooted traditional belief in filial piety (xiao), family remains the cornerstone of major support for young children and elders alike, though the role of the state is becoming more paramount and critical.

\section{CONCLUSION}

The socioeconomic developments of recent decades have put Chinese families at the crossroads of traditional and modern values. They have challenged many traditional practices, such as the change of residential patterns from patrilocal to neolocal. The last decade also witnessed an increased divorce rate in many parts of China. Chinese urban youths have adopted more liberal attitudes toward marriage and family. For instance, more youths today favor childfree marriages than before, and they are more accepting of cohabitation and premarital sex.

However, the inevitable changes in family dynamics will not eradicate family roles and functions. Chinese families remain the cornerstone of support. Though family size is getting smaller, researchers have coined a new term-networked families-to describe the fact that families maintain 
in close proximity toward each other and reciprocity is still a recurring theme. Marriage and family strengths identified by Chinese include harmony, affection, the ability to adapt to changes, equity in marriage, mutual trust, compatibility, and family support. The majority of couples report a satisfactory relationship. In terms of support, with the high female labor force participation rate, families are still responsible for child care and child socialization. Without a universal social security system, they are also responsible for elder care. Chinese culture, being collective in nature, still emphasizes that family needs take precedence over individual needs.

Meanwhile, challenges have surfaced as a result of economic growth and development. Major issues facing urban families include the division of household chores, only children's education and socialization, financial issues, and in-laws issues; whereas, issues facing less advantaged rural families are money and the division of household labor. There is also concern that the only-child generation may not have the wherewithal to take care of their older generation, and therefore, it is necessary for the development of state-level programs to implement support at the family level.

\section{REFERENCES}

Breault, K. D., \& Kposowa, A. J. (1987). Explaining divorce in the United States: A study of 3,111 counties, 1980. Journal of Marriage and the Family, 49, 549-558.

Chen, X., \& Silverstein, M. (2000). Intergenerational social support and the psychological well-being of older parents in China. Research on Aging, 22, 43-65.

Chinese Population Information and Research Center (1990). Beijing: Beijing Institute of Economics Press.

Chow, N. (1999). Diminishing filial piety and the changing role and status of the elders in Hong Kong. International Journal of Aging, 1, 67-77.

Chui, F. (1994). Married women's attitudes toward marriage and spouse selection. Population and Economy, 3, 30-37.

Ding, S. (1992). Trends in current Shanghai families. Social Sciences, 3, 42-46.

Dong, X. P. (2001). DINC families: Contemporary youths' attitudes towards childbirth. Contemporary Youth Study, 6, 39-42.

Du, J. M. (1992). The traditional family. In D. Liu (Ed.), New perspectives on Chinese culture. Beijing: ShangLing Publishing.

Falbo, T. (1982). The one-child family in the United States: Research issues and results. Studies in Family Planning, 13, 212-215.

Falbo, T., \& Poston, D. L. (1993). The academic, personality, and physical outcomes of only children in China. Child Development, 64, 18-35. 
Falbo, T., Poston, D. L., Ji, G., Jiao, S., Jing, Q., Wang, S., Gu, Q., Yin, H., \& Liu, Y. (1989). Physical achievement and personality characteristics of Chinese children. Journal of Biosocial Science, 21, 483-495.

Fei, X. D., \& Xie, S. (1995). The Shanghai suburban women in recent decades. Shanghai: Shanghai Academy of Social Sciences.

Fei, X. D. (1983). The issue of elder care amid the change of family structure. Beijing University News, 3, 6-15.

Fei, X. D. (1982). On changes of Chinese family structure. Tienjing Social Sciences, 3, 2-6.

Fong, V. (2005). Only hope: Coming of age under China's one-child policy. Stanford: CA: Stanford University.

$\mathrm{Fu}$, H. (1988). On unhappy marriages. Guangzhou Study, 8, 42-45.

Glenn, N. D., \& Supancic, M. (1984). The social and demographic correlates of divorce and separations in the United States: an update and reconsideration. Journal of Marriage and the Family, 46, 563-585.

Glenn, N. D., \& Shelton, B. A. (1985). Regional difference in divorce in the United States. Journal of Marriage and the Family, 47, 641-652.

Gui, S. X. (1988). A report from mainland China: Status and needs of rural elderly in the suburbs of Shanghai. Journal of Cross-Cultural Gerontology, 3, 149-167.

Ho, D. Y. F. (1981). Traditional patterns of socialization in Chinese society. Acta Psychologica Taiwanica, 23, 81-95.

Hsu, J. (1985). The Chinese family: Relations, problems and therapy. In W. Tseng, \& D. Y. H. Wu (Eds.), Chinese culture and mental health (pp. 95-112). Orlando, FL: Academic Press.

Hu, R., \& Ye, N. (1991). The nine-city survey on aging in 1988. Tianjin: Tianjin Educational Press.

Jiao, S., Ji, G., \& Jing, Q. (1986). Comparative study of behavioral qualities of only children and sibling children. Child Development, 57, 357-361.

Lei, J. (1994). Changes in rural marriages in recent decades. Beijing: Beijing University Publisher.

Liu, B. (1996). Contemporary marriages in Shanghai. Shanghai: Shanling Publisher.

Li, Y. H. (1989). Research on love. Social Sciences Study, 12, 33-42.

Li, Y. H. (Fall, 1996). The investigation and study of marriage quality in Beijing. China Social Sciences Quarterly, 63-66.

Li, G., \& Xu, A. Q. (2004). Youth's mate selection in the marriage market. Shanghai: Shanghai Academy of Social Sciences.

Liu, C., Munakat, T., Fujiyama, H., \& Usuba, M. (2003). Mental health and psychosocial factors with single child high school students in a city of China. Nippon Koshu Eisei Zasshi, 50, 15-26.

Lo, P., \& Fen, Y. (2001). On college students' marriage attitudes: A gendered perspective. Wuhan University Press, 5, 631-635.

Lu, S. H. (1997). Data analysis of marriage attitudes and changes. Social Sciences Study, 2, 37-47.

Pan, S., \& Jen, J. (2000). Chinese college students' sexual attitudes and behaviors. Beijing: Business Publisher.

Pan, S. (1995). Sex in China. Beijing: Guangmin Daily Publisher. 
Pan, Y. K. (1987). Marriages and families in urban China. Shangdong: Shangdong People's Publisher.

Pan, Y. K., \& Ruan, D. Q. (1995). Chinese urban family networks. Zhejiang Academic Journal, 3, 66-71.

Pan, Y. K., Roger, J., Bien, F., Bien, Y., Guan, Y., \& Lu, H. L. (1997). Housing and family structure in urban China. Social Sciences Study, 6, 69-79.

Pei, X., \& Pillai, V. (1999). Old age support in China: The role of the state and the family. International Journal of Aging and Human Development, 49, 197-212.

Polit, D. F., \& Falbo, T. (1987). Only children and personality development: A quantitative review. Journal of Marriage and Family, 49, 309-325.

Poston, D. L., \& Falbo, T. (1990). Academic performance and personality traits of Chinese children: “Onlies” versus others. American Journal of Sociology, 96, 433-451.

Research on Sex Education among College Students (2001). An investigation of Chinese college students' sexual behaviors in 2000. Youth Study, 12, 31-39.

Sa, J. (1995). Contemporary Chinese women. Beijing: Beijing University Press.

Shen, Chen \& Gao (2000)

Shen, S., \& Yang, S. H. (1995). Family studies of urban China. Beijing: Chinese Social Sciences Publisher.

State Statistics Bureau (1990). Chinese statistics annually. Beijing: Chinese Statistics Publisher.

State Statistics Bureau (1996). Chinese statistics annually. Beijing: Chinese Statistics Publisher.

State Statistics Bureau (2005). Chinese statistics annually. Beijing: Chinese Statistics Publisher.

Stinnett, N., \& DeFrain, J. (1985). Secrets of strong families. Boston: Little, Brown.

$\mathrm{Su}, \mathrm{S} .$, \& Hu, Z. P. (2000). Together and separate: Chinese youths' value perspective. Shanghai: Shanghai Academy of Social Sciences.

The Second Investigation of Chinese Women's Social Status (2001). Data report on the second investigation of Chinese women's social status. Women Studies, 5, 4-12.

Treas, J., \& Wang, W. (1993). Of deeds and contracts: Filial piety perceived in contemporary Shanghai. In V. Bengston, \& A. Achenbaum (Eds.), The changing contract across generations. New York: Aldine de Gruyter.

Tsui, M., \& Rich, L. (2002). The only child and educational opportunity for girls in urban China. Gender and Society, 16, 74-92.

Tseng, W., Juotai, T., Hsu, J., Jinghua, C., Lian, Y., \& Kameoka, V. (1988). Family planning and child mental health in China: The Nanjing Survey. America Journal of Psychiatry, 145, 1396-1403.

Tu, E. J., Freeman, V. A., \& Wolf, D. A. (1993). Kinship and family support in Taiwan, Research on Aging, 15, 465-86.

Unger, J. (1993). Urban families in the Eighties. In Davis, D., \& Hareel, S. (Eds.), Chinese families in the post-Mao era. Berkeley: University of California Press.

Wan, C., Fan, C., Lin, G., \& Jing, Q. (1994). Comparison of personality traits of only and sibling school children in Beijing. The Journal of Genetic Psychology, 155, 377-388.

Wang, W., Du, W., Liu, P., Liu, J., \& Wang, Y. (2000). Five-factor personality measures in Chinese university students: Effects of one-child policy. Psychiatry Research, 109, 37-44. 
Wong, M. G. (1998). The Chinese American family. In C.H. Mindel, R. W. Habenstein, \& R.Wright (Eds.), Ethnic families in America. NJ: Prentice Hall.

Xie, X., Xia, Y., \& Zhou, Z. (2004). Strengths and stress in Chinese immigrant families: A qualitative study. Great Plains Research, 14, 203-218.

Xie, X., DeFrain, J., Meredith, W., \& Combs, R. (1996). Family strengths as by university students and government employees in the People's Republic of China. International Journal of Sociology of the Family, 26, 7-27.

Xie, X., Xia, Y., \& Zhou, Z. (2004). Strengths and stress in Chinese immigrant families: A qualitative study. Great Plains Research, 14, 203-218.

$\mathrm{Xu}, \mathrm{A}$. J. (1995). The situation and changes of urban family and social networks. Shanghai Academy of Social Sciences Academic Journal, 2, 77-85.

$\mathrm{Xu}, \mathrm{A} . \mathrm{Q}$. (1997). Love and marriage among Chinese at the turn of the century. Beijing: Chinese Social Sciences Publisher.

$\mathrm{Xu}, \mathrm{A} . \mathrm{Q}$. (2000). Standard of spouse selection: Reasons for changes in the past 50 years. Social Sciences Study, 6, 18-30.

Xu, A. Q., \& Ye, W. L. (2002). Research report on Chinese marriages. Beijing: Chinese Social Sciences Publisher.

Xu, A. Q., \& Ye, W. L. (1999). Chinese marriages. Beijing: Chinese Social Sciences Publisher.

$\mathrm{Xu}, \mathrm{A} . \mathrm{Q}$. (1997). Love and marriage among Chinese at the turn of the century. Beijing: Chinese Social Sciences Publisher.

Xu, A. Q. (1995). Investigation of Chinese family structures: A sociological and demographic perspective. Jenjian Study, 1, 72-76.

Yang, B., Ollendick, T. H., Dong, Q., Xia, Y., \& Lin, L. (1995). Only children and children with siblings in the People's Republic of China: Levels of fear, anxiety, and depression. Child Development, 66, 1301-1311.

Yang, H. (1996). The distributive norm of monetary support to older parents: A look at a township in China. Journal of Marriage and the Family, 58, 404-416.

Zhan, H. J. (2004a). Willingness and expectations: Intergenerational differences in attitudes toward filial responsibility in China. Marriage \& Family Review, 36, 175-200.

Zhan, H. J. (2004b). Socialization or social structure: Investigating predictors of attitudes toward filial responsibility among Chinese urban youth from one and multiple-child families. The International Journal of Aging and Human Development, 59, 105-124.

Zhan, H. J., \& Montgomery, R. J. V. (2003). Gender and elder care in China: The influence of filial piety and structural constraints. Gender and Society, 17, 209-220.

Zhang, Y., Kohnstamm, G. A., Cheung, P. C., \& Lau, S. (2001). A new look at the old "little emperor": Developmental changes in the personality of only children in China. Social Behavior and Personality, 29, 725-732.

Zhang, M. J. (1994). Divorce in Jenjian province. Jenjian Study, 6, 67-71.

Zhang, Y. J. (2001). Support networks for urban and rural senior citizens. Social Sciences Study, 4, 11-21.

Zhen, N., Zhang, S., Li, M. H., Mao, G. Y., \& Wang, J. (2000). Sexuality among contemporary Chinese college students. Tienjing: Tienjing University Press.

doi:10.1300/J002v41n01_08 